\title{
Surface Modification of Poly(GMA-co-EDMA-co-MMA) with Resorcarenes
}

\author{
Alver A. Castillo-Aguirre, ${ }^{a}$ Betty A. Velásquez-Silva, ${ }^{a}$ Cindy Palacio, ${ }^{a}$ Frank Baez, ${ }^{a}$ \\ Zuly J. Rivera-Monroy ${ }^{a}$ and Mauricio Maldonado ${ }^{*}, a$ \\ ${ }^{a}$ Departamento de Química, Facultad de Ciencias, Universidad Nacional de Colombia, \\ Sede Bogotá, Carrera 30 No. 45-03, 11001 Bogotá, Colombia
}

\begin{abstract}
Surface modification of poly(GMA-co-EDMA-co-MMA), whose synthesis was performed by copolymerization of 2,3-epoxypropyl methacrylate (GMA), methyl methacrylate (MMA), and ethylene glycol dimethacrylate (EDMA), was compared between aliphatic and aromatic substituted resorcarenes. The copolymer surface was modified by reacting with resorcarenes, and the vibrational properties of the modified copolymers were investigated via attenuated total reflectance Fourier transform infrared (ATR-FTIR) and Raman spectroscopies in dry state at room temperature. Those analysis showed that only tetra( $p$-hydroxyphenyl)resorcarene was linked to the copolymer, the reaction was regioselective with the crown conformer. Additionally, quantification of incorporated macrocyclic was performed, specifically, the maximum fixation of resorcarene in the copolymer was $95 \%$ when employing two molar resorcarene excesses per glycidyl residue. The modification was carried out in both acidic and basic medium and it was established that the polymer is modified with the aromatic resorcarene only in basic medium, while the reaction in basic medium with aliphatic resorcarenes produces their corresponding tetrasodium salt.
\end{abstract}

Keywords: resorcarene, surface modification, copolymerization, open chain reaction

\section{Introduction}

Interest in polymer surface modifications using macrocyclic systems has increased in recent years. As an example, the use of macrocyclic ligands such as crown ethers ${ }^{1}$ or calixarenes ${ }^{2}$ in the surface modification of stationary phases for analytical separations can be mentioned. In this field, the use of resorcarenes as a macrocyclic molecules for surface modification has made a significant contribution to the development of new applications, including separation techniques and heterogeneous catalysts, among others. Resorcarenes represent a class of macrocyclic phenolic compounds obtained from the condensation reaction of resorcinol with several aldehydes in acidic solutions, ${ }^{3}$ and they can be modified with various substituents on the upper and lower rim to provide specific functionality and selectivity. The many possible structural variations lead to potential applications as voltammetric sensors, ${ }^{4}$ dendrimer synthesis, ${ }^{5,6}$ dyeing of fibers, ${ }^{7,8}$ nuclear magnetic resonance (NMR) solvating agents, ${ }^{9,10}$ chemical receptors for molecules and ions ${ }^{11-13}$ and absorption of heavy metal ions, ${ }^{14,15}$ besides, resorcarene derivatives can be absorbed or covalently

*e-mail: mmaldonadov@unal.edu.co bound to multiple surface types. Thus resorcarenes are used in high performance liquid chromatography (HPLC) for modification of the stationary phase, and the process involves the lower rim of the resorcarene derivate with polar carbonate groups covalently bonded to a silica substrate. ${ }^{16}$ Resorcarenes covalently linked by their upper rim to silica particles, which have been used as new stationary phases ((3-(C-methylcalix[4]resorcinarene)-2-hydroxypropoxy)propylsilyl-appended silica particles (MCR-HPS) and bromoacetate-substituted MCR-HPS particles (BAMCRHPS)), have been also reported. ${ }^{17}$

For surface modification, the use of 2,3-epoxypropyl methacrylate (GMA) copolymers has been continuously growing, due to their successful applications in various process. ${ }^{18-21}$ Copolymers of GMA are commercially available, bearing reactive oxirane groups. These oxirane groups present in the polymer chain can easily undergo an opening reaction with nucleophilic reagents that contain hydroxyl, carboxyl or amine groups..$^{22-24}$

To continue with our studies related to the chemical reactivity of resorcarenes, in the present investigation the reaction efficiency of the glycidyl residue, in poly(2,3-epoxypropyl methacrylate-coethylene glycol dimethacrylate-co-methyl methacrylate) 
(poly(GMA-co-EDMA-co-MMA)), is evaluated using some resorcarenes, specifically, tetrapropylresorcarene (1), tetrabutylresorcarene (2), tetrapentylresorcarene (3) and tetra( $p$-hydroxyphenyl)resorcarene (4). Modified copolymers were analyzed via attenuated total reflectance Fourier transform infrared spectroscopy (ATR-FTIR) and Raman spectroscopy in the dry state at room temperature. This showed that only tetra( $p$-hydroxyphenyl)resorcarene was linked to the copolymer. It was found that the glycidylmethacrylate oxirane opening reaction by using tetra(p-hydroxyphenyl)resorcarene proceeds selectively at the lower rim hydroxyl group without a reaction of the upper rim hydroxyl groups, observing that this trend in solid phase is similar to that observed in solution. ${ }^{25}$

\section{Experimental}

\section{General information}

All chemical reagents were acquired from commercial suppliers and used without further purification. The structures of resorcarenes were confirmed by NMR spectroscopy. Raman spectra were recorded on a Thermo Scientific DXR Raman microscope with the Raman shift in $\mathrm{cm}^{-1}$. A Thermo Fisher Scientific Nicolet iS10 FT-IR spectrometer was used for collecting ATR-FTIR spectra in the region of $600-4000 \mathrm{~cm}^{-1} .{ }^{1} \mathrm{H}$ NMR spectra were recorded in DMSO- $d_{6}$ at $400 \mathrm{MHz}$ on a Bruker Avance 400 instrument. Chemical shifts are reported in ppm, using the residual solvent signal as reference. Thermogravimetric analysis coupled with differential scanning calorimetry (TGA/DSC) was carried out on a Mettler Toledo (TGA/DSC 3+) simultaneous thermal analyzer. $10 \mathrm{mg}$ of each compound was heated from 20 to $600{ }^{\circ} \mathrm{C}$ (heating rate $\left.10{ }^{\circ} \mathrm{C} \mathrm{min}{ }^{-1}\right) .{ }^{26}$ Scanning electron microscopy (SEM) analysis was done on a TESCAN VEGA3 SB microscope. Elemental analysis was recorded on a Thermo Scientific Flash 2000 CHN S-O with thermal conductivity detector.

\section{Synthesis of resorcarenes}

The synthesis of these macrocycles was performed by the reaction between resorcinol and different aldehydes under acidic conditions, as previously described by Maldonado and co-workers. ${ }^{27-29}$

The aldehydes used were butanal, pentanal, hexanal and $p$-hydroxybenzaldehyde. To a resorcinol solution $(0.10 \mathrm{~mol})$ and aldehyde $(0.10 \mathrm{~mol})$ in ethanol:water $(1: 1)$ $(14 \mathrm{~mL})$ it was added dropwise hydrochloric acid $(10 \mathrm{~mL})$ and was reacted at reflux with constant stirring for 1-6 h. The reaction mixture was cooled in an ice bath and the solid material formed was filtered and washed with water to remove traces of acid. The filtrate was dried under vacuum and was characterized by IR and ${ }^{1} \mathrm{H}$ NMR.

\section{Tetrapropylresorcarene (1)}

It was obtained as yellow solid in yield $82 \%$; $\mathrm{mp}>250{ }^{\circ} \mathrm{C}$ decomposition; FTIR (KBr) $v / \mathrm{cm}^{-1} 3318$ $(\mathrm{O}-\mathrm{H}), 1202(\mathrm{C}-\mathrm{O}) ;{ }^{1} \mathrm{H}$ NMR $\left(400 \mathrm{MHz}, \mathrm{DMSO}-d_{6}\right) \delta 0.90$ (t, $\left.12 \mathrm{H}, \mathrm{CH}_{3}\right), 1.20\left(\mathrm{~m}, 8 \mathrm{H}, \mathrm{CH}_{2}\right), 2.08$ (q, 8H, $\left.\mathrm{CH}_{2}\right), 4.23$ $(\mathrm{t}, 4 \mathrm{H}, \mathrm{CH}), 6.15$ (s, $4 \mathrm{H}$, ortho to $\mathrm{OH}), 7.24$ (s, $4 \mathrm{H}$, meta to $\mathrm{OH}), 8.94$ (s, 8H, OH).

\section{Tetrabutylresorcarene (2)}

It was obtained as pale yellow powder in yield of $87 \%$; $\mathrm{mp}>250{ }^{\circ} \mathrm{C}$ decomposition; FTIR (KBr) $\mathrm{v} / \mathrm{cm}^{-1} 3314$ $(\mathrm{O}-\mathrm{H}), 1194(\mathrm{C}-\mathrm{O}) ;{ }^{1} \mathrm{H}$ NMR $\left(400 \mathrm{MHz}, \mathrm{DMSO}-d_{6}\right) \delta 0.90$ (t, $\left.12 \mathrm{H}, \mathrm{CH}_{3}\right), 1.23\left(\mathrm{~m}, 16 \mathrm{H},\left(\mathrm{CH}_{2}\right)_{2}\right), 2.11$ (q, 8H, $\mathrm{CH}_{2}$ ), $4.23(\mathrm{t}, 4 \mathrm{H}, \mathrm{CH}), 6.15$ (s, 4H, ArH, ortho to $\mathrm{OH}), 7.26$ (s, $4 \mathrm{H}, \mathrm{ArH}$, meta to $\mathrm{OH}), 8.94$ (s, $8 \mathrm{H}, \mathrm{OH})$.

\section{Tetrapentylresorcarene (3)}

It was obtained as yellow solid in yield 98\%; $\mathrm{mp}>250{ }^{\circ} \mathrm{C}$ decomposition; FTIR (KBr) $v / \mathrm{cm}^{-1} 3415$ (O-H), $1292(\mathrm{C}-\mathrm{O}) ;{ }^{1} \mathrm{H}$ NMR (400 MHz, DMSO- $\left.d_{6}\right) \delta 0.69$ (t, $\left.12 \mathrm{H}, \mathrm{CH}_{3}\right), 1.19$ (br s, 24H, $\left.\left(\mathrm{CH}_{2}\right)_{3}\right), 1.93\left(\mathrm{~m}, 8 \mathrm{H}, \mathrm{CH}_{2}\right.$ ), 4.19 (br s, 4H, CH), 6.22 (s, 4H, ArH, ortho to $\mathrm{OH}$ ), 7.22 (s, $4 \mathrm{H}, \mathrm{ArH}$, meta to $\mathrm{OH}), 9.02$ (s, 8H, OH).

\section{Tetra( $p$-hydroxyphenyl)resorcarene (4)}

It was obtained as purple solid in yield $87 \% ; \mathrm{mp}>250^{\circ} \mathrm{C}$ decomposition; FTIR (KBr) v / $\mathrm{cm}^{-1} 3380(\mathrm{O}-\mathrm{H}), 1176$ $\left(\mathrm{C}-\mathrm{O}\right.$ ); ${ }^{1} \mathrm{H}$ NMR (400 MHz, DMSO- $\left.d_{6}\right) \delta$ 5.39-5.50 (s, $4 \mathrm{H}, \mathrm{ArCH}$ ), 5.84-6.57 (m, 24H, ArH), 8.29-8.40 (s, 8OH, $\mathrm{ArOH}$ ), 8.61-8.80 (s, 4OH, ArOH), see Figures S2 and S3 in Supplementary Information (SI) section.

\section{Copolymer preparation}

The monomer inhibitor (hydroquinone monomethyl ether, MEHQ) was removed before performing the polymerization reaction, using a silica gel column. A mixture of GMA (1.35 mL, $10.20 \mathrm{mmol})$, MMA $(0.45 \mathrm{~mL}$, $4.20 \mathrm{mmol}$ ), EDMA (1.20 mL, $6.36 \mathrm{mmol}), 1,1$-azobis(cyclo hexanecarbonitrile) ( $33.9 \mathrm{mg}, 0.15 \mathrm{mmol})$, and cyclohexanol $(4.50 \mathrm{~mL}, 42.60 \mathrm{mmol})$ was prepared and then was incubated at $57^{\circ} \mathrm{C}$ for $24 \mathrm{~h}$. Next, the resulting polymer was cooled to room temperature, cyclohexanol was removed by washing with absolute ethanol, and the polymer was dried under reduced pressure. ${ }^{30,31}$ Poly(GMA-co-EDMA-co-MMA) was obtained as a white compact solid. FTIR (ATR) $\mathrm{v} / \mathrm{cm}^{-1} 2988$, $2947(\mathrm{C}-\mathrm{H}), 1723$ (C=O), 1147 (C-O). 


\section{Copolymer functionalization}

\section{In basic medium}

The functionalization process was adapted from the methodology proposed by Dan and co-workers. ${ }^{32}$ Briefly, a mixture of $1(0.2 \mathrm{mmol})$ in $N, N$-dimethylformamide (DMF, $3.0 \mathrm{~mL})$ and sodium hydroxide $(0.2 \mathrm{mmol})$ was added to triturated copolymer poly(GMA-co-EDMA-coMMA) (500 mg) and then the reaction was incubated at $57{ }^{\circ} \mathrm{C}$ for $15 \mathrm{~h}$. The resulting solid was cooled to room temperature, washed with DMF and ethanol absolute, and dried under reduced pressure. For other functionalization reactions of copolymer poly(GMA-co-EDMA-co-MMA), the procedure mentioned above was applied, exchanging the resorcarene $\mathbf{1}$ for resorcarenes $\mathbf{2 , 3}$ and 4, respectively. The solid products were characterized via ATR-FTIR and Raman spectroscopy. After removing the copolymer by filtration and DMF evaporation, the resorcarene that did not react was determined gravimetrically.

Tetrasodium 2,8,14,20-tetrapropylpentacyclo $\left[19 \cdot 3 \cdot 1 \cdot 1^{3,7} \cdot 1^{9,13} \cdot 1^{15,19}\right.$ ]octacosa-1(25),3,5,7(28),9,11,13(27), $15,17,19(26), 21,23$-dodecaene-4,10,16,22-tetraol6,12,18,24-tetrakis(olate) (5) was obtained as a creamcolored powder at a yield of $45 \%$; mp $>250{ }^{\circ} \mathrm{C}$ decomposition; FTIR (KBr) v / cm c $^{-1} 3319$ (O-H), 1210 (C-O), 1609 (aromatic ring), 2929 (alkyl chains); ${ }^{1} \mathrm{H}$ NMR $\left(400 \mathrm{MHz}, \mathrm{DMSO}-d_{6}\right) \delta 0.91\left(\mathrm{t}, 12 \mathrm{H}, \mathrm{CH}_{3}\right), 1.22(\mathrm{~m}$, $8 \mathrm{H}, \mathrm{CH}_{2}$ ), 2.15 (q, 8H, $\mathrm{CH}_{2}$ ), 4.18 (t, 4H, CH), 6.05 (s, $4 \mathrm{H}$, ortho to $\mathrm{OH}), 7.25$ (s, $4 \mathrm{H}$, meta to $\mathrm{OH}), 9.56(\mathrm{~s}, 4 \mathrm{H}$, $\mathrm{OH}) ;{ }^{13} \mathrm{C}$ NMR $\left(100 \mathrm{MHz}, \mathrm{DMSO}-d_{6}\right) \delta 13.9\left(\mathrm{CH}_{3}\right), 20.8$ $\left(\mathrm{CH}_{2}\right), 32.6\left(\mathrm{CH}_{2}\right), 34.9(\mathrm{CH}), 102.8,124.0,132.4,152.3$ (resorcinol ring).

\section{In acid medium}

In order to determine whether the functionalization reaction proceeded in acid medium, the procedure proposed by Dan and co-workers ${ }^{32}$ was modified, and it was used $\mathrm{H}_{2} \mathrm{SO}_{4}$. A mixture of $4(0.2 \mathrm{mmol})$ in DMF $(3.0 \mathrm{~mL})$ and sulfuric acid solution ( $5 \%$ in DMF, $0.25 \mathrm{~mL}$ ) was added to triturated copolymer poly(GMA-co-EDMA-co-MMA)
(500 mg) and then the reaction was incubated at $57^{\circ} \mathrm{C}$ for $15 \mathrm{~h}$. The resulting solid was cooled to room temperature, washed with DMF and ethanol absolute, and dried under reduced pressure. The product was characterized via ATR-FTIR and Raman spectroscopy.

\section{Results and Discussion}

Scheme 1 represents the general procedure for the formation of resorcarenes $\mathbf{1 - 4}$. The synthesis was done through the acid-catalyzed cyclocondensation of resorcinol with the respective aldehyde in a mixture of ethyl alcohol and water $(1: 1)$ at $75{ }^{\circ} \mathrm{C}$, in a similar manner to that described in the literature. ${ }^{33}$ The products were purified by means of recrystallization. These derivatives were characterized using spectral techniques, including FTIR and ${ }^{1} \mathrm{H}$ NMR (see Experimental section). Compounds had been previously synthesized by other authors, ${ }^{33-35}$ and our spectroscopic data agreed with those reported.

The general scheme of the copolymer synthesis is illustrated in Scheme 2. Since the composition of the reaction mixture has a great influence on the final copolymer structural characteristics, several parameters concerning the polymerization reaction, such as the amount of GMA, EDMA, and MMA and the ratio of cyclohexanol, were optimized. The optimum conditions were as follows: $1.35 \mathrm{~mL}$ of GMA, $0.45 \mathrm{~mL}$ of MMA, $1.20 \mathrm{~mL}$ of EDMA, $33.9 \mathrm{mg}$ of 1,1-azobis(cyclohexanecarbonitrile), and $4.50 \mathrm{~mL}$ of cyclohexanol at $57^{\circ} \mathrm{C}$. These conditions were in agreement with previous reports. ${ }^{24,36}$ Characterization of the copolymer was done via ATR-FTIR, thermogravimetric analysis, and scanning microscopy study.

ATR-FTIR spectrum shows a characteristic signal corresponding to a $\mathrm{C}=\mathrm{O}$ bond at $1714 \mathrm{~cm}^{-1}$. In addition, other characteristic peaks were found at 2930 and $3104 \mathrm{~cm}^{-1}$ due to the $\mathrm{C}-\mathrm{H}$ stretching vibration, $1449 \mathrm{~cm}^{-1}$ due to the $\mathrm{C}-\mathrm{H}$ bending vibration, $1151 \mathrm{~cm}^{-1}$ due to the $\mathrm{C}-\mathrm{O}$ stretching vibration of the glycidyl group and $902 \mathrm{~cm}^{-1}$ due to characteristic epoxy ring absorption. The results showed that there was an absence of the $\mathrm{C}=\mathrm{C}$ peak at $1600-1675 \mathrm{~cm}^{-1}$,

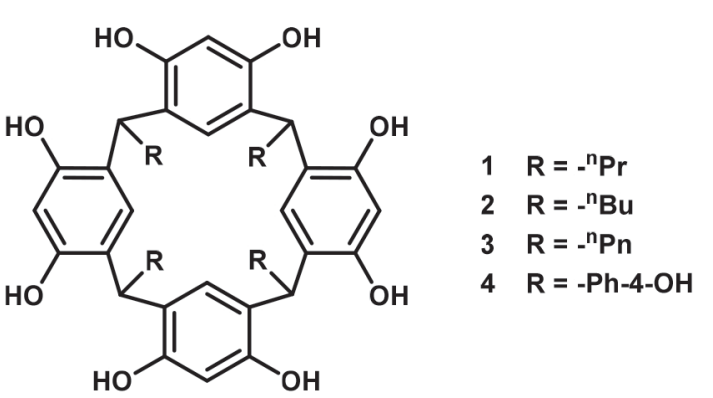


<smiles>C=C(C)C(=O)OCC1CO1</smiles>

GMA

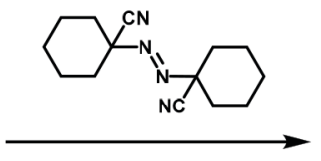

$\mathrm{CyOH}, 57^{\circ} \mathrm{C}, 24 \mathrm{~h}$<smiles>C=C(C)C(=O)OCCOC(=O)C(=C)C</smiles>

EDMA

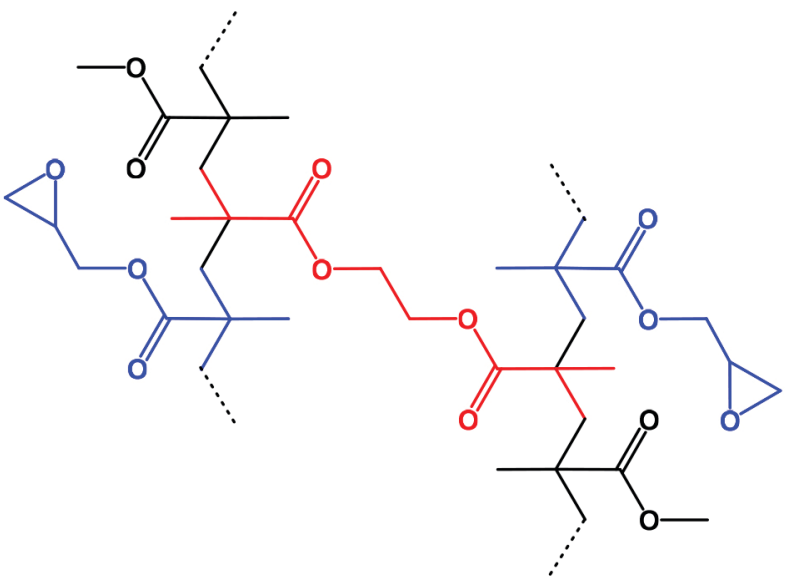

Scheme 2. One-pot synthesis of poly(GMA-co-EDMA-co-MMA).

which suggested that the polymerization method was effective. The thermal stability of the copolymer was evaluated via thermogravimetric analysis (TGA). According to Figure 1a, two stages of thermal decomposition were observed for the copolymer. The first one occurs close to $110^{\circ} \mathrm{C}$, and the second one is a dramatic decomposition (over $355^{\circ} \mathrm{C}$ ). These results corroborate the behavior of the copolymer observed in previous reports. ${ }^{37}$ So the copolymer is thermostable below $100{ }^{\circ} \mathrm{C}$ and can even be used up to $120^{\circ} \mathrm{C}$ for short periods of time in the process of the fixation.

(a)

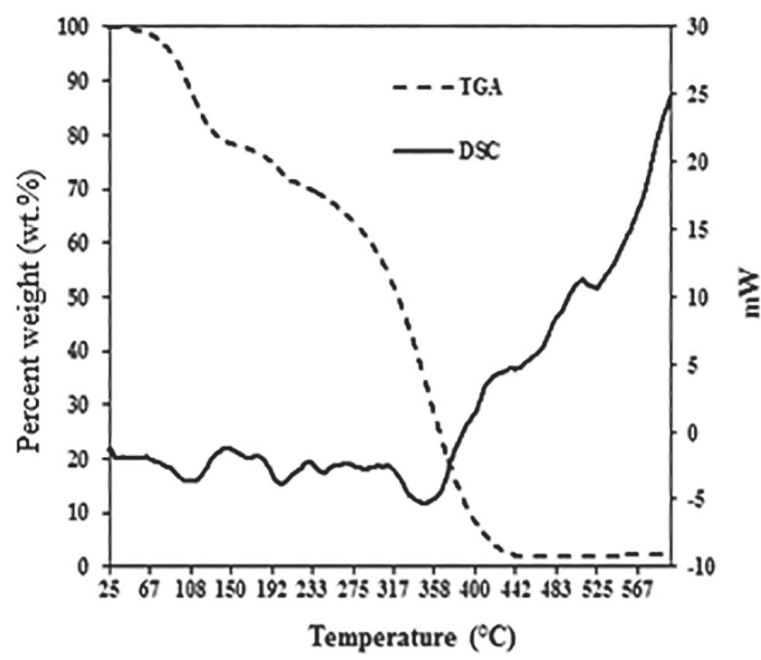

This temperature is suitable, since the reaction is carried out at $57{ }^{\circ} \mathrm{C}$. GMA-copolymer morphology was analyzed via SEM imaging (Figures 1b-e). It was observed that the morphology of the GMA-copolymer is quite uniform, with continuous pores. The uniform and rich open-pore structure is suitable for mass transfer efficiency for the reaction between the oxirane side chain of GMA-copolymer and the resorcarenes 1-4.

As mentioned above, the presence of an oxirane ring in GMA-copolymers allows further chemical modifications

(b)
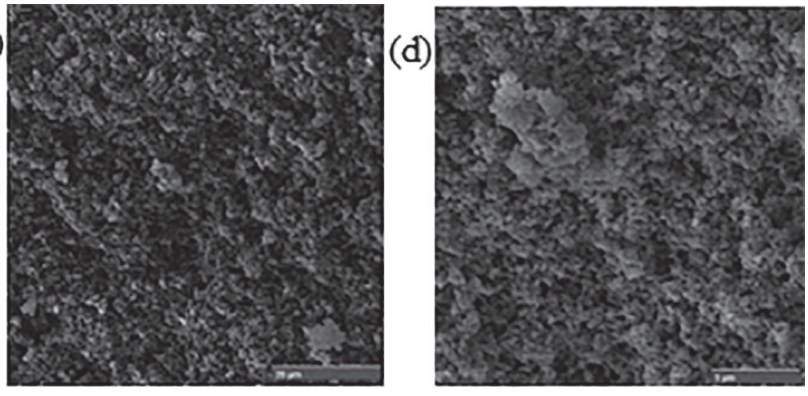

(c)

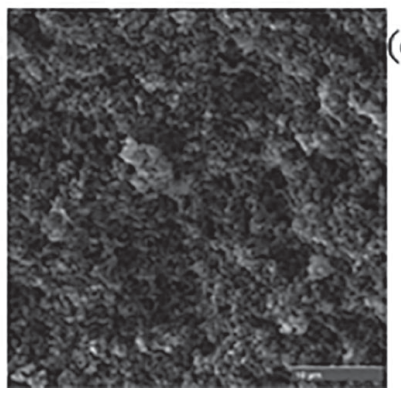

Figure 1. Copolymer poly(GMA-co-EDMA-co-MMA). (a) TGA/DSC thermograms. Micrographs at different magnifications: (b) $20 \mu \mathrm{m}$, (c) $10 \mu \mathrm{m}$, (d) $5 \mu \mathrm{m}$ and (e) $2 \mu \mathrm{m}$. 


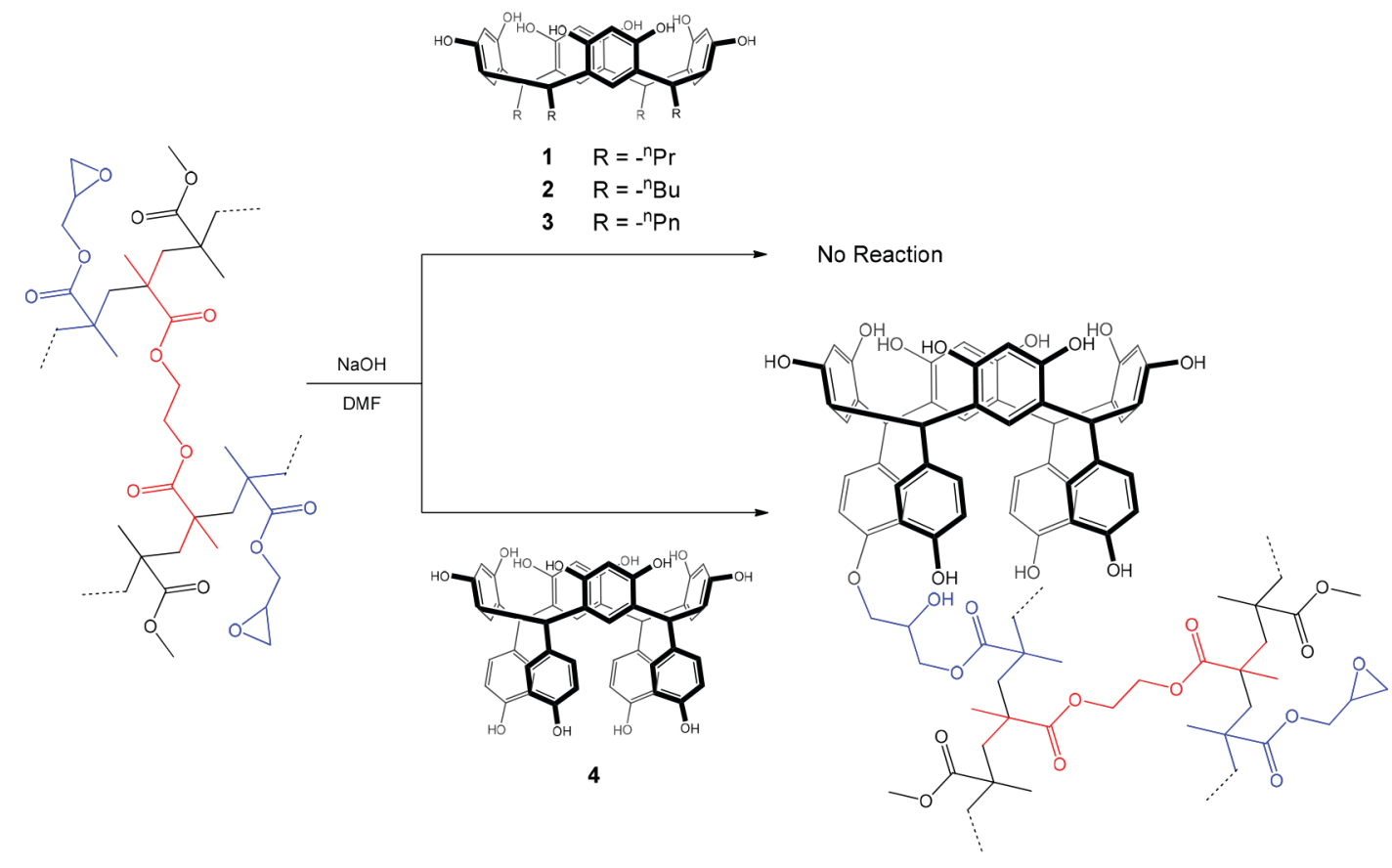

Scheme 3. Reaction of poly(GMA-co-EDMA-co-MMA) with resorcarenes.

for various applications. In recent years, research has been carried out on the attachment of a hydroxyl group to copolymers of GMA. ${ }^{32,36}$ For the present research, we performed the fixation of each resorcarene molecule (1-4) by its direct reaction with the copolymer's glycidyl group in basic media (Scheme 3) and acid media. Modified copolymers were purified and then characterized using ATR-FTIR and Raman spectroscopy in the dry state at room temperature.

The products obtained from the reaction between poly(GMA-co-EDMA-co-MMA) copolymer and resorcarenes 1-3 present ATR-FTIR spectra showing a similar profile compared with the unmodified copolymer, suggesting that under the used reaction conditions there is no fixation of these resorcarenes. While, the analysis of the major peaks observed in the ATR-FTIR spectrum of modified copolymer using resorcarene 4 (Figure 2, dotted red line) showed the presence of broad and intense absorption at $3371 \mathrm{~cm}^{-1}$ corresponding to the $\mathrm{O}-\mathrm{H}$ groups of resorcarene rings, the presence of intense peaks at 1651 and $1591 \mathrm{~cm}^{-1}$ corresponding to $\mathrm{C}=\mathrm{C}$ of aromatic ring and the peak at $1363 \mathrm{~cm}^{-1}$ attributed to $\mathrm{C}-\mathrm{O}$ of phenolic residue. The absorption at $902 \mathrm{~cm}^{-1}$ in unmodified copolymer spectrum is characteristic of epoxy ring of GMA. The intensity reduction of this band, in modified copolymer spectrum, suggests that epoxy ring was opened during the reaction and this result indicated that resorcinarene $\mathbf{4}$ was chemically bound to poly(GMA-co-EDMA-co-MMA). The ATR-FTIR spectra of the starting copolymer and product modified with resorcarene $\mathbf{4}$ are shown in Figure 2.

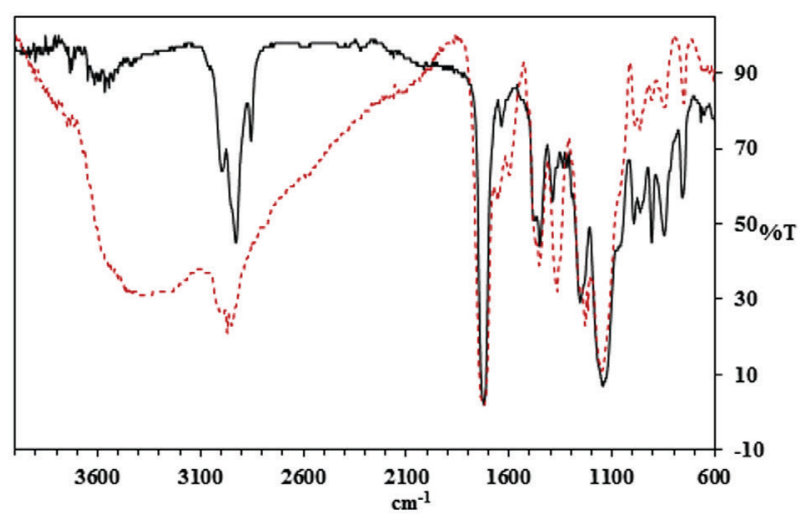

Figure 2. ATR-FTIR analysis of copolymers. Unmodified (black solid line), and modified copolymer with resorcarene 4 (red dotted line).

To confirm the results obtained with ATR-FTIR spectroscopy, the samples were analyzed by Raman spectroscopy. Products obtained from the reaction between copolymer and resorcarenes 1-3, in basic media, show a similar profile compared with the unmodified copolymer (Figures 3a-d). However, when resorcarene 4 was used, the modified copolymer Raman spectrum exhibits different signals compared to the unmodified material; specifically, absorption at $3057 \mathrm{~cm}^{-1}$ is present. This signal is characteristic of aromatic systems and confirms that the resorcarene $\mathbf{4}$ was the only macrocycle fixed at the copolymer surface. Our results suggest that the reaction does not occur with the upper rim hydroxyl groups of the tested resorcarenes under the above described procedures.

To better understand the results obtained with resorcarenes 1-3, the reaction between $\mathbf{1}$ and the copolymer 


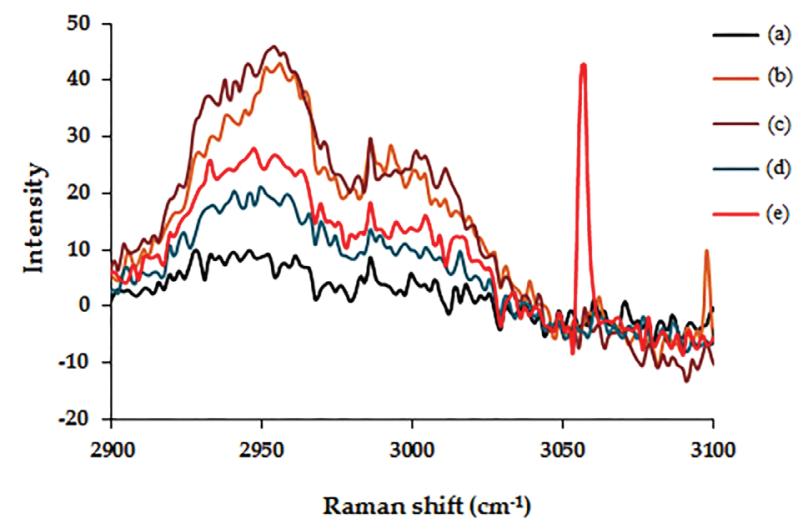

Figure 3. Raman analysis of copolymers. (a) Unmodified, and modified copolymer with resorcarene (b) 1, (c) 2, (d) 3 and (e) 4 .

poly(GMA-co-EDMA-co-MMA) was studied as a model. After performing the reaction according to the methodology described above in basic medium, the obtained mixture was separated by filtration and the solid was washed with DMF and ethanol. The resulting filtrate was slowly evaporated to give a solid product, which was analyzed by ATR-FTIR, ${ }^{1} \mathrm{H}$ and ${ }^{13} \mathrm{C}$ NMR. The ATR-FTIR spectrum of the product showed aromatic ring $\left(1609 \mathrm{~cm}^{-1}\right)$, alkyl chain $\left(2929 \mathrm{~cm}^{-1}\right)$ and hydroxyl group (3421 $\left.\mathrm{cm}^{-1}\right)$ absorptions. ${ }^{1} \mathrm{H}$ NMR spectrum displayed characteristic signals of propyl chains $(0.91,1.45$, 1.22 and $2.15 \mathrm{ppm}$ ), a methylene bridge fragment between the aromatic rings (4.18 ppm), and aromatic hydrogen of a tetrasubstituted resorcinol unit (6.05 and $7.25 \mathrm{ppm}$ ). For the proton of hydroxyl group the signal appears at 9.57, but this signal integrates only for four protons (Figure 4).

${ }^{13} \mathrm{C}$ NMR spectrum of the isolated product (Figure S5, SI section) shows the signals corresponding to propyl chains (13.9, 20.8 and $32.6 \mathrm{ppm})$ and aromatic carbons (102.8, 124.0, 132.4 and $152.3 \mathrm{ppm})$. In this way, the signal at $34.9 \mathrm{ppm}$ confirmed the presence of a methylene bridge fragment between the aromatic rings. The information allowed to identify the product as tetrasodium 2,8,14,20-tetrapropyl pentacyclo[19.3.1.1 $\left.1^{3,7} \cdot 1^{9,13} \cdot 1^{15,19}\right]$ octacosa-1(25),3,5,7(28),9,11,13(27),15,17,19(26), 21,23-dodecae-ne-4,10,16,22-tetraol-6,12,18,24tetrakis(olate) (5). Thus, our results shows that the modification of poly(GMA-co-EDMA-co-MMA) with aliphatic resorcarenes does not occur, since the phenolate is formed, and it is a species that is stabilized by hydrogen bonding with the hydroxyl group. This phenomenon was verified when the reactions of copolymer with resorcarenes $\mathbf{2}$ and $\mathbf{3}$, in alkaline medium, were carried out, obtaining also the corresponding tetrasodic salt product. Therefore, it is necessary to propose the previous functionalization of the aliphatic resorcarenes for the subsequent modification of the polymer.

Reaction of 4 and the copolymer poly(GMA-coEDMA-co-MMA), as mentioned above, allowed the

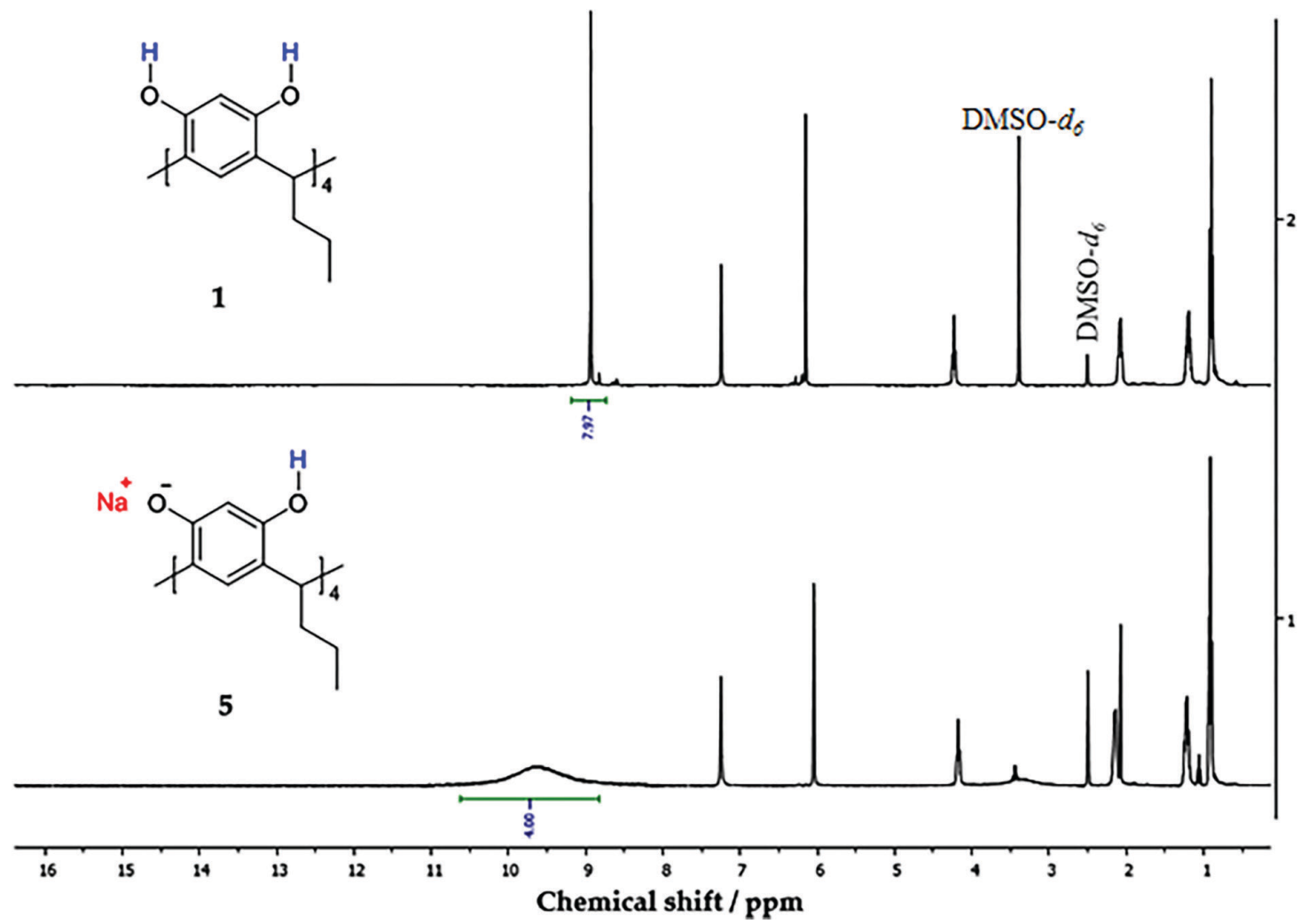

Figure 4. ${ }^{1} \mathrm{H}$ NMR spectra (400 MHz, DMSO- $d_{6}$ ) of compounds $\mathbf{1}$ and $\mathbf{5}$. 


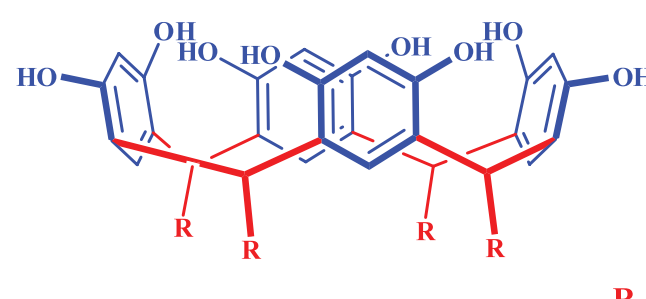

\section{Crown}

Figure 5. Conformations of tetra( $p$-hydroxyphenyl)resorcarene.

fixation of macrocyclic at the surface of the copolymer. The reaction was carried out using the crude product of $\mathbf{4}$, which is a conformational mixture of two isomers (chair and crown conformers, see Figure 5). To evaluate whether the two conformational isomers were fixed on the surface of the copolymer, after separating and washing the modified copolymer, the filtrate was concentrated to half the volume with the formation of a solid product, which was isolated and characterized via ${ }^{1} \mathrm{H}$ NMR. The ${ }^{1} \mathrm{H}$ NMR spectrum of the product displayed three different hydroxyl moieties at $8.64 \mathrm{ppm}$, assigned to hydroxyl groups in the lower rim, and two signals at 8.34 and $8.36 \mathrm{ppm}$, corresponding to two classes of hydroxyl groups attached to resorcinol residues in the macrocyclic system. Careful analysis of all the patterns confirmed the structure of chair conformer (Figure 5). According to this analysis, the crown conformer of $\mathbf{4}$ was the one fixed on the copolymer surface, maintaining the selective character of the process previously observed in solution. ${ }^{25}$

In order to determine if the medium influenced the modification of the polymer, the reaction was performed with resorcarene $\mathbf{4}$ in acidic and basic medium. In both reactions the oxirane rupture is generated by producing diol (2,3-dihydroxypropyl methacrylate) or its isomer (1,3-dihydroxypropyl methacrylate), the latter being a minor product. ${ }^{38}$ However, the use of an acid medium does not allow the deprotonation of the hydroxyl groups of the lower rim, avoiding the nucleophilic attack of the resorcarene 4. Both polymers were analyzed by FT-Raman spectroscopy (Figure 6) and it can be observed, in the alkaline medium, the signal at $3227 \mathrm{~cm}^{-1}$, corresponding to aromatic systems, and at $1259 \mathrm{~cm}^{-1}$, corresponding to ether.

Finally, once the best conditions for the fixation of $\mathbf{4}$ were established, the optimum quantity of resorcarene required to modify $1 \mathrm{~g}$ of copolymer was evaluated. The amount of modified copolymer was calculated using the residual resorcarene determined gravimetrically, as it was mentioned above. For functionalization reaction, different molar ratios between epoxy group and resorcarene $\mathbf{4}$

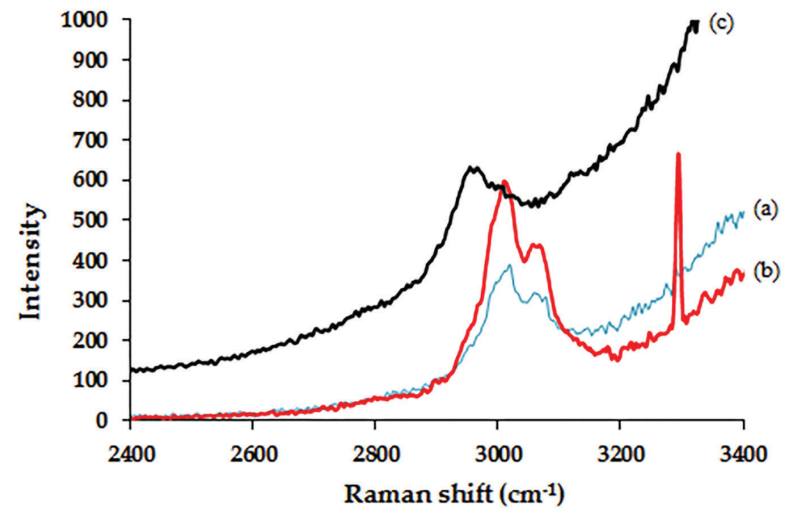

Figure 6. Raman analysis of modified poly(GMA-co-EDMA-co-MMA) with 4. (a) Acid media; (b) basic media; (c) unmodified.

were used. The maximum fixation of resorcarene in the copolymer was $95 \%$ when employing two molar resorcarene excesses per glycidyl residue.

\section{Conclusions}

A copolymer with three components, GMA, MMA, and EDMA poly(GMA-co-EDMA-co-MMA), was produced and characterized via thermogravimetric analysis (TGA/DSC), scanning electron microscopy (SEM), and ATR-FTIR spectroscopy. The copolymer was treated under basic conditions with different macrocyclic systems, specifically tetrapropylresorcarene, tetrabutylresorcarene, tetrapentylresorcarene and tetra( $p$-hydroxyphenyl) resorcarene. ATR-FTIR and Raman spectroscopy results showed that only tetra( $p$-hydroxyphenyl)resorcarene was covalently bonded to the copolymer, indicating that the reaction is selective towards the hydroxyl groups of the lower rim of tetra( $p$-hydroxyphenyl)resorcarene, while aliphatic resorcarenes produce salt. The results observed for the reaction (over the monolithic surface) between the epoxide ring and the studied resorcarene $\mathbf{4}$ suggest that this reaction is regioselective and stereoselective under described conditions. The reaction was carried out in acid medium and it was found that modification of the 
polymer with aromatic resorcarene under this condition does not occur. Finally, it was determined that fixation of resorcinarens could be up to $95 \%$, using two molar excess.

\section{Supplementary Information}

Supplementary data (structure of compounds $\mathbf{4}$ and 5; ${ }^{1} \mathrm{H}$ and ${ }^{13} \mathrm{C}$ NMR spectra of compound 4 and ${ }^{13} \mathrm{C}$ NMR spectrum of compound 5) are available free of charge at http://jbcs.sbq.org.br as PDF file.

\section{Acknowledgments}

We gratefully acknowledge the support of Colciencias (project: 110165843141, contract: FP44842-037-2015) and the Universidad Nacional de Colombia, Sede Bogotá. Alver A. Castillo-Aguirre and Betty A. Velásquez-Silva thank the program Colciencias Doctorado Nacional No. 647 for financing their PhD studies.

\section{References}

1. Paik, M.; Kang, J.; Huang, B.; Carey, J.; Lee, W.; J. Chromatogr. A 2013, 1274, 1.

2. Mutihac, L.; Lee, J.; Kim, J.; Vicens, J.; Chem. Soc. Rev. 2011, 40, 2777.

3. Högberg, A. G.; J. Org. Chem. 1980, 45, 4498.

4. Wang, F.; Wu, Y.; Lu, K.; Ye, B.; Electrochim. Acta 2013, 87, 756.

5. Cortez-Maya, S.; Hernández-Ortega, S.; Ramírez-Apan, T.; Lijanova, I. V.; Martínez-García, M.; Bioorg. Med. Chem. 2012, 20,415 .

6. Lijanova, I. V.; Moggio, I.; Arias, E.; Klimova, T.; MartínezGarcía, M.; Tetrahedron 2008, 64, 10258.

7. Kazakova, E. K.; Morozova, J. E.; Mironova, D. A.; Konovalov, A. I.; J. Inclusion Phenom. Macrocyclic Chem. 2012, 74, 467.

8. Jain, V. K.; Kanaiya, P. H.; Bhojak, N.; Fibers Polym. 2008, 9 , 720.

9. O'Farrell, C. M.; Chudomel, J. M.; Collins, J. M.; Dignam, C. F.; Wenzel, T. J.; J. Org. Chem. 2008, 73, 2843.

10. Wenzel, T. J.; J. Inclusion Phenom. Macrocyclic Chem. 2014, $78,1$.

11. Beyeh, N. K.; Weimann, D. P.; Kaufmann, L.; Schalley, C. A.; Rissanen, K.; Chem. - Eur. J. 2012, 18, 5552.

12. Salorinne, K.; Weimann, D. P.; Schalley, C. A.; Nissinen, M.; Eur. J. Org. Chem. 2009, 6151.

13. Hayashida, O.; Uchiyama, M.; Tetrahedron Lett. 2006, 47, 4091.

14. Jumina; Sarjono, R. E.; Siswanta, D.; Santosa, S. J.; Ohto, K.; J. Korean Chem. Soc. 2011, 55, 454.
15. Gramage-Doria, R.; Armspach, D.; Matt, D.; Coord. Chem. Rev. 2013, 257, 776.

16. Ruderisch, A.; Iwanek, W.; Pfeiffer, J.; Fischer, G.; Albert, K.; Schurig, V.; J. Chromatogr. A 2005, 1095, 40.

17. Tan, H.; Soh, S.; Zhao, J.; Yong, E.; Gong, Y.; Chirality 2011, 23, E91.

18. Vergara-Barberán, M.; Lerma-García, M. J.; Simó-Alfonso, E. F.; Herrero-Martínez, J. M.; Anal. Chim. Acta 2016, 917, 37.

19. Chen, Y.; Deng, N.; Wu, C.; Liang, Y.; Jiang, B.; Yang, K.; Liang, Z.; Zhang, L.; Zhang, Y.; Talanta 2016, 154, 555.

20. Jiao, X.; Shen, S.; Shi, T.; J. Chromatogr. B 2015, 1007, 100.

21. Perçin, I.; Khalaf, R.; Brand, B.; Morbidelli, M.; Gezici, O.; J. Chromatogr. A 2015, 1386, 13.

22. Morinaga, H.; Tsuneishi, F.; Taniguchi, S.; Kawakami, G.; Tetrahedron Lett. 2014, 55, 3768.

23. Lv, Y.; Mei, D.; Pan, X.; Tan, T.; J. Chromatogr. B 2010, 878, 2461.

24. Safa, K. D.; Nasirtabrizi, M. H.; Eur. Polym. J. 2005, 41, 2310.

25. Castillo-Aguirre, A.; Rivera-Monroy, Z.; Maldonado, M.; Molecules 2017, 22, 1660.

26. Poomalai, P.; Varghese, T. O.; Siddaramaiah; ISRN Mater. Sci. 2011, 2011, ID 921293.

27. Velásquez-Silva, A.; Cortés, B.; Rivera-Monroy, Z.; PérezRedondo, A.; Maldonado, M.; J. Mol. Struct. 2017, 1137, 380.

28. Sanabria, E.; Esteso, M.; Pérez, A.; Vargas, E.; Maldonado, M.; Molecules 2015, 20, 9915.

29. Franco, L.; Salamanca, Y.; Maldonado, M.; Vargas, E.; J. Chem. Eng. Data 2010, 55, 1042.

30. Vlakh, E. G.; Tennikova, T. B.; J. Sep. Sci. 2007, 30, 2801.

31. Merhar, M.; Podgornik, A.; Barut, M.; Žigon, M.; Štrancar, A.; J. Sep. Sci. 2003, 26, 322.

32. Ge, F.; Huang, Y.; Luo, Y.; Jiang, L.; Dan, Y.; RSC Adv. 2014, 4, 63118 .

33. Tunstad, L. M.; Tucker, J. A.; Dalcanale, E.; Weiser, J.; Bryant, J. A.; Sherman, J. C.; Helgeson, R. C.; Knobler, C. B.; Cram, D. J.; J. Org. Chem. 1989, 54, 1305.

34. Aoyama, Y.; Tanaka, Y.; Sugahara, S.; J. Am. Chem. Soc. 1989, 111, 5397.

35. Yamakawa, Y.; Ueda, M.; Nagahata, R.; Takeuchi, K.; Asai, M.; J. Chem. Soc. Perkin Trans. 1 1998, 4135.

36. Lv, Y.; Mei, D.; Pan, X.; Tan, T.; J. Chromatogr. B 2010, 878, 2461.

37. Acquah, C.; Danquah, M. K.; Moy, C. K. S.; Ongkudon, C. M.; J. Appl. Polym. 2016, 133, 43507.

38. Shaw, S. E.; Russo, T.; Solomon, D. H.; Qiao, G. G.; Polymer (Guildf). 2006, 47, 8247.

Submitted: March 2, 2018

Published online: April 10, 2018 